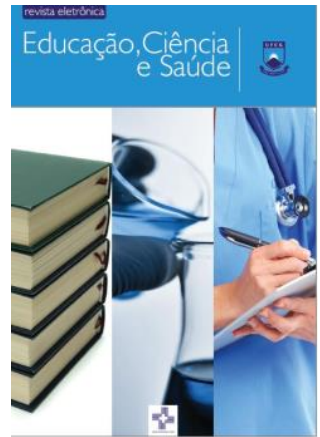

EDUCAÇÃO CIÊNCIA E SAÚDE

http://dx.doi.org/10.20438/ecs.v8i1.395

\title{
ANÁLISES FÍSICO-QUÍMICAS DE ÁGUAS DE CHAFARIZES DO MUNICÍPIO DE CORONEL EZEQUIEL-RN
}

\author{
Ana Maria de Souza Araújo1, Lorena Vanessa Medeiros Dantas¹, Breno do \\ Nascimento Ferreira ${ }^{1}$, José Romildo Cazé Ferreira² ${ }^{2}$ Denise Domingos da \\ Silva ${ }^{3}$
}

${ }^{1}$ Curso de Licenciatura em Química, Lab. de Biocombustíveis e Química Ambiental, Unidade Acadêmica de Biologia e Química, Universidade Federal de Campina Grande, Cuité-PB, Brasil.

${ }^{2}$ Curso de Bacharelado em Farmácia, Lab. de Biocombustíveis e Química Ambiental, Unidade Acadêmica de Saúde, Universidade Federal de Campina Grande, Cuité-PB, Brasil.

${ }^{3}$ Prof ${ }^{a}$ Unidade Acadêmica de Biologia e Química, Lab. de Biocombustíveis e Química Ambiental, Universidade Federal de Campina Grande, Cuité-PB, Brasil.

Email para correspondência: denise.domingos@professor.ufcg.edu.br

\section{Resumo}

\begin{abstract}
Considerando a importância da água para a manutenção da vida e a necessidade de ter informações sobre a qualidade das águas consumidas, percebesse o quanto é importante realizar análises para saber as condições físico-químicas e o padrão de potabilidade em que estas se encontram. Devido a escassez e a falta de recursos hídricos que atingem principalmente o Nordeste, a população para sobreviver e desenvolver suas atividades têm usufruído de águas provenientes de chafarizes. Assim, o presente estudo teve por objetivo determinar algumas propriedades físicoquímicas de águas provenientes de chafarizes situados no município de Coronel Ezequiel-RN, onde foram realizadas medições de $\mathrm{pH}$, turbidez, condutividade elétrica, dureza, alcalinidade, teor de cloreto e identificação de sódio e potássio por fotometria de chama. Em relação aos resultados, pode-se perceber que todos os parâmetros analisados neste estudo estão de acordo com o valor máximo permitido pela Portaria de Consolidação № 5/2017 do Ministério da Saúde, tornando as amostras como próprias para o consumo humano.
\end{abstract}

Palavras-chave: águas, chafariz, qualidade.

\begin{abstract}
Considering the importance of water for the maintenance of life and the need to have information about the quality of the water consumed, it is been realized the importance to carry out analyzes to know the physical-chemical conditions and the standard of potability in which they are found. Due to the scarcity and lack of water resources that affect mainly the Northeast, the population has been using water from fountains for surviving and developing their activities. Thus, this study aimed to determine some physico-chemical properties of water from fountains located in the municipality of Coronel Ezequiel-RN, where measurements of $\mathrm{pH}$, turbidity, electrical
\end{abstract}


conductivity, hardness, alkalinity, chloride content and identification of sodium and potassium by flame photometry. Regarding the results, it can be seen that all parameters analyzed in this study are in accordance with the maximum values allowed by the Consolidation Ordinance No. 5/2017 of the Ministry of Health, making the samples suitable for human consumption.

Keywords: water, fountain, quality.

\section{Introdução}

A água é um meio fundamental para a sobrevivência e desenvolvimento dos seres vivos, como também para a área industrial, além disso é uma substância bastante abundante na Terra.

Segundo Menezes et. al (2015) e Gomes (2011), a água cobre cerca de $70 \%$ da superfície da Terra, mais de $97 \%$ da água do planeta são águas salgadas e estão nos oceanos e mares, não serve nem para uso industrial. A água doce representa apenas $3 \%$ da água total, cerca de $2 \%$ da água doce estão congeladas nos círculos polares, os quais cobrem $10 \%$ da superfície da Terra, e somente $0,6 \%$ da água doce está disponível diretamente para o consumo humano. Destes 0,6\%, 97\% correspondem a águas subterrâneas e apenas 3\% apresentam-se na forma de água superficial nos lagos e rios de extração mais fácil.

Considerando a importância da água para a manuntenção da vida e sabendo da necessidade de se ter informações sobre a qualidade das águas consumidas, percebesse o quanto é importante realizar análises para saber as condições fisíco-químicas e o padrão de potabilidade que estas se encontram.

De acordo com Alcoforado (2015), a população mundial já consome $50 \%$ de água doce disponível no mundo e que em 40 anos o percentual de consumo aumentará até $80 \%$ de utilização de água doce da terra. Entretanto, esse dado é preocupante, pois há uma grande má distribuição desse recurso para a população.

Desse modo apesar do planeta Terra ser rico em águas, estas geralmente são caracterizadas como impróprias para o consumo humano. Logo, tornasse evidente a necessidade da realização de análises antes das águas serem consumidas, pois as características das referidas águas podem estar em desacordo com os requisitos de potabilidade estabelecidos na Portaria do Ministério da Saúde. 
Segundo Araújo (2015), a água para o abastecimento doméstico deve apresentar características sanitárias e toxicológicas adequadas, e não apresentar microrganismos patogênicos e substâncias nocivas à saúde, com pretensões de prevenir danos e promover o bem-estar das pessoas .

O uso de águas inapropriadas para o consumo humano pode ocasionar danos à saúde dos seus consumidores, desde doenças mais simples a mais complexas. Algumas patologias que acometem os seres humanos estão relacionadas à qualidade da água, dentre elas, podem ser citadas como exemplo: hepatite A e E, cólera, febre tifoide, doenças entéricas e diarreicas causadas por bactérias, parasitas e vírus (ANA, 2013).

O Brasil é um país que sofre muito com a escassez e falta de recursos hídricos, em algumas regiões como o Nordeste, esse problema é ainda mais frequente. O Brasil apesar de dispor de uma grande quantidade de água, cerca de $12 \%$ de toda água superficial do mundo, apresenta quadros de escassez em muitas regiões, o número de pessoas que são atingidas pela falta de água é cada vez maior (LUNA, 2011).

De acordo com Soares (2014), a escassez de água causa uma grande consequência que interfere no desenvolvimento das regiões tanto no meio natural como na melhoria de vida das pessoas, principalmente nas áreas povoadas mais necessitadas.

Devido à escassez e a falta de recursos hídricos que atingem principalmente a região do Nordeste brasileiro, a população para sobreviver e desenvolver suas atividades têm usufruído de águas provenientes de outras fontes. Atualmente, diversas são as fontes utilizadas para o suprimento de água, tais como: águas subterrâneas (poços), água de chuva (cisterna), e águas superficiais (açudes). (LORDELO et al, 2018).

Segundo Costa et al. (2012), águas subterrâneas são de extrema importância, principalmente como reservatório de água doce que se encontra disponível para os seres vivos. Em conformidade Nunes (2014) afirma que os chafarizes surgiram para atender a demanda por água da população, em especial a periférica, sendo implantados pelo poder público e acarretando conforto aos bairros mais populosos das cidades, entretanto, esse modelo de abastecimento público, desde seu surgimento permite acesso a água sem tratamento. 
As águas encontradas em chafarizes raramente passam por algum tipo de análise ou tratamento antes de serem utilizadas, destacando-se assim a importância da realização de análises que possam vir a determinar sua qualidade. Diante disto, o presente estudo teve como objetivo determinar algumas propriedades físico-químicas de águas provenientes de chafarizes situados no município de Coronel Ezequiel-RN.

\section{Metodologia}

\section{1 Área de Estudo}

A área de estudo localiza-se no município de Coronel Ezequiel-RN, situado no Nordeste brasileiro, na Borborema Potigar, na Região do Trairí e próximo a fronteira com o Estado da Paraíba. Segundo os dados do IBGE (2010), a cidade dispõe de uma área de $185,8 \mathrm{~km}^{2}$, população de 5.405 habitantes, e densidade demográfica de 29,6 hab $/ \mathrm{km}^{2}$, com latitude de $06^{\circ} 23^{\prime}$ " "Sul, longitude de $36^{\circ}$ 12 ' 47 "' Oeste e altitude de 561 metros. O município fica vizinho aos municípios de Jaçanã, Carrapateira e São Bento do Trairí.

Figura 1: Mapa e localização das duas amostras de Coronel Ezequiel-RN.

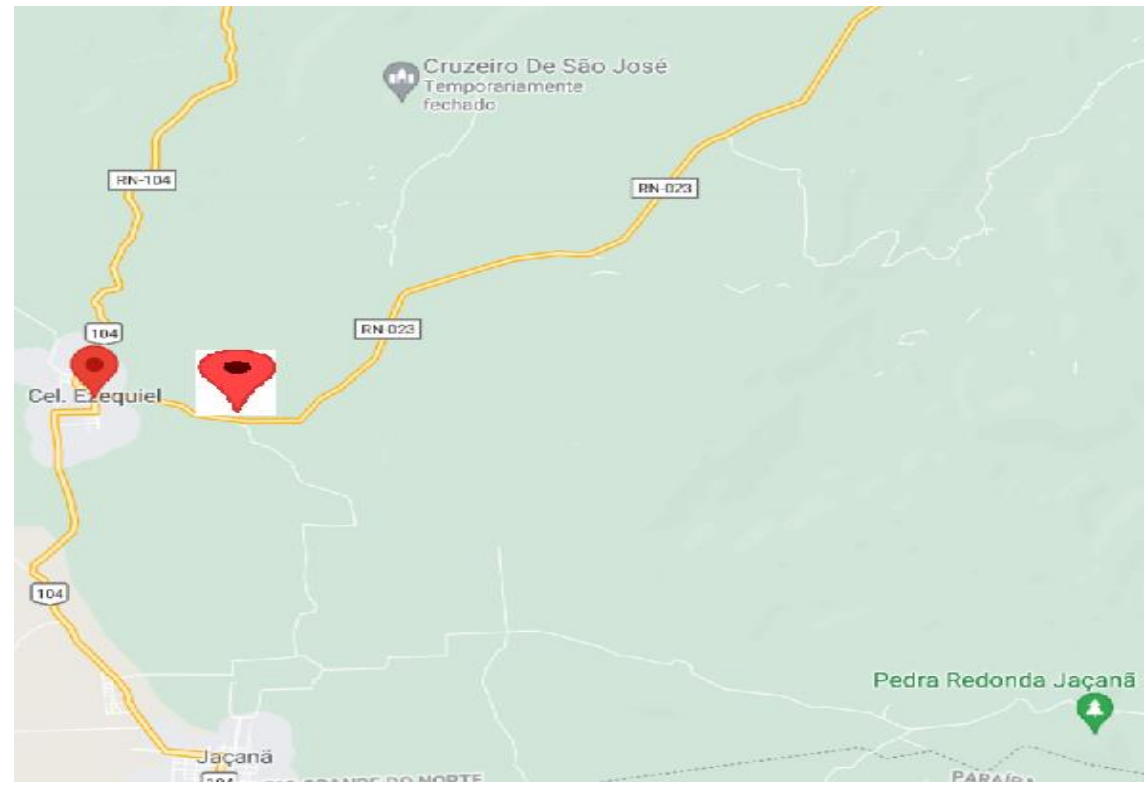

Fonte: Google Maps, 2021. 


\subsection{Amostragem e coleta das amostras}

Para o desenvolvimento da presente pesquisa foram selecionados 2 chafarizes localizados no município de Coronel Ezequiel-RN, onde foram coletadas 3 amostras de cada ponto, estas foram identificadas e armazenadas em garrafas de politereftalato de etileno (PET) com capacidade de 2,0L previamente higienizadas, preenchidas por completo e mantidas em refrigeração até a análise, com o intuito de evitar alterações nas características das mesmas. As amostras foram coletadas no período de novembro de 2019, o quadro 1 informa a localização dos chafarizes.

Quadro 1: Localização dos chafarizes.

\begin{tabular}{|c|c|}
\hline Amostra & Localidade \\
\hline Ponto A - Chafariz 1 & $\mathrm{RN}-023$ \\
\hline Ponto B - Chafariz 2 & $\mathrm{RN}-023$ \\
\hline
\end{tabular}

Fonte: Dados da pesquisa, 2019.

\subsection{Determinação de propriedades físico-químicas das amostras}

As análises das amostras foram realizadas em triplicata no laboratório de Biocombustíveis e Química Ambiental da Universidade Federal de Campina Grande/Cuité-PB e seguiu-se de metodologias recomendadas pelo manual prático de análise de água da Fundação Nacional da Saúde (FUNASA) e do Standard Methods for the Examination of Water and Wastewater (APHA).

\subsection{Potencial hidrogeniônico $(\mathrm{pH})$}

Para determinação das medidas de $\mathrm{pH}$ foi utilizado um peagâmetro $\mathrm{pH}$ 21-Hanna, sendo o mesmo previamente calibrado com soluções tampão ácido de 4,01 $\pm 0,01$ e neutro de 7,01 $\pm 0,01$.

\subsection{Turbidez}

O parâmetro de turbidez foi determinado por um turbidímetro modelo DLT-WV, previamente calibrado com soluções padrões de < 0,10 NTU, 10 NTU, 100 NTU e 800 NTU. 


\subsection{Condutividade Elétrica}

A condutividade elétrica foi determinada utilizando um condutivímetro AT-255, previamente calibrado com uma solução padrão de cloreto de potássio (KCl) $146,9 \mu \mathrm{S} / \mathrm{cm}$ a uma temperatura padronizada de $25^{\circ} \mathrm{C}$.

\subsection{Dureza}

Para determinação da dureza foi utilizado o método clássico de volumetria de complexação utilizando como agente titulante o EDTA (ácido etilenodiaminotetracético) com a concentração de $0,01 \mathrm{~mol} . \mathrm{L}^{-1}$ e como indicador o negro de Eriocromo - T (NET) com pH 9,4 (APHA,2006).

\subsection{Alcalinidade}

As medidas de alcalinidade foram realizadas pelo método de volumetria de neutralização com ácido sulfúrico 0,02 M como agente titulante e solução indicadora alaranjado de metila 0,1 M (FUNASA, 2013).

\subsection{Cloretos}

Na determinação de cloretos foi utilizado a volumetria de precipitação com Nitrato de Prata 0,1 M pelo método de Mohr, e como indicador o Cromato de Potássio 0,1 M (FUNASA, 2013).

\subsection{Identificação de potássio e sódio por fotômetro de chama}

Para a determinação dos cátions metálicos, $\mathrm{Na}^{+}$e $\mathrm{K}^{+}$foi utilizado um fotômetro de chama QUIMIS Q498M. O aparelho foi calibrado com soluções padrão de 100 ppm de $\mathrm{Na}^{+}$e $\mathrm{K}^{+}$. Logo, as amostras de águas foram sendo analisadas com as respectivas concentrações e determinando a coloração da chama específica de cada substância (QUIMIS, 2011).

\section{$3 \quad$ Resultados}

Os resultados obtidos na presente pesquisa à respeito das amostras de águas de chafarizes coletadas no município de Coronel Ezequiel-RN estão expressos nas tabelas abaixo. 


\subsection{Análise de $\mathrm{pH}$, condutividade elétrica e turbidez}

$\mathrm{O}$ pH refere-se a concentração do íon hidrogênio de uma solução e varia de 0 a 14 , indicando assim a intensidade de acidez $(\mathrm{pH}<7,0)$, neutralidade $(\mathrm{pH}=7,0)$ ou alcalinidade $(\mathrm{pH}>7,0)$ de uma solução aquosa. De acordo com Von Sperling (2014), o pH da água não é capaz de causar danos à saúde pública, abrindo exceção para valores extremamente ácidos ou alcalinos, podendo causar irritação na pele ou olhos.

A condutividade elétrica é determinada pela possibilidade de uma solução conduzir a passagem de corrente elétrica, isto dependendo da presença de cátions ou ânions. Sendo assim, quanto maior a concentração iônica da solução, maior é a oportunidade para ação eletrolítica e, portanto, maior a capacidade em conduzir corrente elétrica (APHA, 2006).

A turbidez é um parâmetro que é definido como uma característica física de amostras de água que reduz a sua transparência à passagem de luz através do líquido, onde a alteração decorre da presença de material em suspensão.

A tabela 1 apresenta os valores médios de $\mathrm{pH}$, condutividade elétrica e turbidez obtidos no estudo realizado nos chafarizes do município de Coronel Ezequiel-RN e seus respectivos desvios padrão.

Tabela 1: Valores médios de $\mathrm{pH}$, condutividade elétrica e turbidez dos chafarizes.

\begin{tabular}{cccc}
\hline $\begin{array}{c}\text { Pontos } \\
\text { analisados }\end{array}$ & $\begin{array}{c}\text { Valores médios } \\
\text { de } \mathbf{p H}\end{array}$ & $\begin{array}{c}\text { Condutividade elétrica } \\
(\boldsymbol{\mu S} / \mathbf{c m})\end{array}$ & Turbidez (NTU) \\
\hline Ponto A & $7,1 \pm 0,3$ & $187,3 \pm 1,8$ & $0,5 \pm 0,1$ \\
Ponto B & $7,1 \pm 0,1$ & $179,6 \pm 4,4$ & $0,8 \pm 0,2$ \\
& & & \\
VMP* $^{*}$ & 6,0 a 9,5 & Não especificado & 5,0 NTU \\
\hline
\end{tabular}

Fonte: Dados da pesquisa, 2019.

Analisando a tabela acima, é possível perceber que os valores médios de $\mathrm{pH}$ dos chafarizes são 7,1 para ambos. Em conformidade, em um estudo realizado por Bezerra et al. (2017) em chafarizes do município de Fortaleza-CE os valores obtidos de $\mathrm{pH}$ variaram entre 4,8 e 7,6. De acordo com a Portaria de Consolidação do Ministério da Saúde n 5/2017 do Ministério da Saúde (MS), 0 pH da água deve ser mantido na faixa de 6,0 a 9,5 (BRASIL, 2017). Sendo assim, 
os valores de $\mathrm{pH}$ das amostras analisadas atendem aos requisitos estabelecidos.

No que se diz respeito à análise da condutividade elétrica não há um valor máximo permitido na Portaria para se considerar uma condutividade elétrica ideal, porém é possível perceber que os valores obtidos foram considerados baixos, 179,6 e $187,3 \mu \mathrm{S} / \mathrm{cm}$.

Observando a tabela 1, percebe-se que a turbidez das amostras é de 0,5 e 0,8 NTU. Portanto, encontra-se de acordo com o padrão estabelecido pelo MS, onde o valor máximo é de 5,0 NTU. Em conformidade um estudo realizado por Santos et al. (2019) em águas do Chafariz Municipal de Cuité-PB, para o parâmetro de turbidez os valores encontrados nos pontos $A$ e $B$ foram 0,28 e 0,31 NTU, respectivamente.

\subsection{Análise de dureza total, cloretos e alcalinidade}

A dureza é a concentração de cátions multimetálicos em solução, os cátions frequentemente associados são cálcio e magnésio $\left(\mathrm{Ca}^{2+}, \mathrm{Mg}^{2+}\right)$, a dureza pode ser classificada como temporária ou permanente. De acordo com a FUNASA (2013), a dureza da água em $\mathrm{mg} / \mathrm{L}$ de carbonato de cálcio $\left(\mathrm{CaCO}_{3}\right)$ pode ser caracterizada como: mole ou branda: < $50 \mathrm{mg} / \mathrm{L}$ de $\mathrm{CaCO}_{3}$; dureza moderada: entre 50 mg/L e 150 mg/L de $\mathrm{CaCO}_{3}$; dura: entre 150 mg/L e 300 mg/L de $\mathrm{CaCO}_{3}$; e muito dura: $>300 \mathrm{mg} / \mathrm{L}$ de $\mathrm{CaCO}_{3}$.

Segundo a FUNASA (2014), altas concentrações do íon cloreto na água podem ocasionar restrições ao seu uso pelo sabor que confere à mesma e pelo efeito laxativo que causam naqueles indivíduos que estavam acostumados a baixas concentrações.

A alcalinidade é a medida da capacidade que a água tem de neutralizar ácidos, além disso é representada pela presença de íons hidróxido, carbonato e bicarbonato e não se constitui em padrão de potabilidade, ficando este efeito limitado apenas pelo valor do $\mathrm{pH}$.

A seguir, a tabela 2 apresenta os resultados das amostras analisadas ao se tratar da dureza, alcalinidade e cloretos, incluindo seus respectivos desvios padrões. 
Tabela 2: Valores médios da dureza, cloretos e alcalinidade das amostras.

\begin{tabular}{cccc}
\hline Pontos analisados & $\begin{array}{c}\text { Dureza } \\
\left(\mathrm{CaCO}_{3} / \mathbf{m g}^{\mathrm{L}-} \mathbf{- 1}\right)\end{array}$ & $\begin{array}{c}\text { Cloretos } \\
(\mathbf{m g} / \mathbf{L})\end{array}$ & $\begin{array}{c}\text { Alcalinidade } \\
(\mathbf{m g} / \mathbf{L})\end{array}$ \\
\hline Ponto $\mathrm{A}$ & $126,1 \pm 0,3$ & $0,4 \pm 0,1$ & $4,4 \pm 0,1$ \\
Ponto B & $103,5 \pm 0$ & $0,4 \pm 0$ & $5,6 \pm 0$ \\
& & & \\
VMP $^{*}$ & $500 \mathrm{CaCO}_{3} / \mathrm{mg}_{\mathrm{L}}{ }^{-1}$ & $250 \mathrm{mg} / \mathrm{L}$ & Não especificado \\
\hline
\end{tabular}

Fonte: Dados da pesquisa, 2019.

Verificando os valores obtidos no que se diz respeito à dureza total das amostras, 126,1 e 103,5 mg/L de $\mathrm{CaCO}_{3}$, é possível perceber que as amostras atendem a condição estabelecida pelo MS, onde a quantidade máxima permitida de $\left|\mathrm{CaCO}_{3}\right|$ para a água ser considerada potável é de $500 \mathrm{mg} / \mathrm{L}$ de $\mathrm{CaCO}_{3}$. Além disso, os valores encontrados neste parâmetro indicam que a dureza das amostas é do tipo moderada e encontram-se de acordo com os valores obtidos no estudo de Santos et al. (2019), onde os resultados encontrados para a dureza total das amostras foram de 113,1 e 360,3 mg/L de $\mathrm{CaCO}_{3}$.

O Ministério da Saúde determina que a quantidade máxima presente de cloretos na água deve ser de $250 \mathrm{mg} / \mathrm{L}$, sendo assim, é possível observar nos dados obtidos na pesquisa que as amostras estão de acordo com o padrão estabelecido devido os teores serem baixos, 0,4 mg/L. De acordo com os dados da pesquisa de Bezerra et al. (2017), em chafarizes do município de FortalezaCE as concentrações de cloreto variaram entre 34,3 e 124,5 mg/L.

Em relação a alcalinidade, não há um valor especificado pelo MS para este parâmetro, entretanto, os valores correspondentes a alcalinidade das amostras foram considerados baixos, 4,4 e $5,6 \mathrm{mg} / \mathrm{L}$.

\subsection{Análise da concentração de sódio e potássio}

$\mathrm{Na}$ tabela 3, estão dispostos os valores obtidos a respeito da concentração de sódio e potássio nas amostras e seus respectivos desvios padrão. 
Tabela 3: Valores médios da concentração de sódio e potássio das amostras.

\begin{tabular}{ccc}
\hline Pontos analisados & Sódio $\left(\mathbf{N a}^{+}\right) \mathbf{( p p m )}$ & Potássio $\left(\mathbf{K}^{+}\right) \mathbf{( p p m )}$ \\
\hline Ponto A & $34,4 \pm 0,7$ & $5,5 \pm 0,3$ \\
Ponto B & $27,4 \pm 3,3$ & $4,3 \pm 0,1$ \\
& & Não especificado
\end{tabular}

Fonte: Dados da pesquisa, 2019.

Percebe-se que as amostras apresentaram baixas concentrações de sódio de 27,4 e 34,4 ppm, se adequando assim ao valor máximo permitido pelo Ministério da Saúde de $200 \mathrm{mg} / \mathrm{L}$ ou ppm. Santos et al. (2019) em seu estudo encontrou valores para as medidas de concentração de sódio de 86,9 \pm 4,3 e $175,4 \pm 16,9$ ppm nas suas amostras, enquanto que na pesquisa de Bezerra et al. (2017) as concentrações de sódio variaram entre 35,9 e 109,1 mg/L.

De acordo com a Tabela 3 é possível perceber que as concentrações de potássio encontradas, 4,3 e 5,5 ppm, também são consideradas baixas, mas não há um valor máximo permitido para este parâmetro. Em conformidade com Santos et al. (2019), as análises das amostras apresentaram concentrações de potássio de 5,1 $\pm 0,4$ e 23,1 $\pm 1,2$ ppm, valores considerados baixos.

Em um estudo realizado por Silva (2019) no município de Jaçanã-RN, próximo ao município de Coronel Ezequiel-RN, as propriedades físico-químicas das amostras analisadas não atenderam aos padrões de potabilidade exigidos pelo Ministério da Saúde, pois as medidas de $\mathrm{pH}$, sólidos totais dissolvidos, concentração de sódio e dureza não se adequaram os valores máximos estabelecidos pela Portaria no 5/2017.

\section{Conclusão}

As análises físico-químicas realizadas nas amostras de águas coletadas nos chafarizes situados no município de Coronel Ezequiel-RN apresentaram resultados significativos a respeito da qualidade destas águas. Sendo assim foi possível perceber que tanto o ponto $A$ como o ponto $B$ atenderam aos padrões de potabilidade exigido pela Portaria de Consolidação № 5/2017 do Ministério da Saúde, pois os valores encontrados na pesquisa para os parâmetros de $\mathrm{pH}$, turbidez, condutividade elétrica, alcalinidade, cloretos, dureza total e concentração de sódio e potássio se adequaram ao valor máximo permitido. 
Contudo, a presente pesquisa torna-se relevante por fornecer dados relevantes tanto a população como a comunidade acadêmica à respeito da qualidade das águas que são distribuídas nos presentes chafarizes do município de Coronel Ezequiel, uma vez que as referidas matrizes aquosas não tinham sido analisadas e por não se ter informações à respeito do padrão de potabilidade das águas que fazem parte desta região.

\section{Referências}

ALCOFORADO, F. A questão da água no mundo e seus imensos desafios. Revista Direito UNIFACS-Debate Virtual, n. 179, 2015.

ANA - AGÊNCIA NACIONAL DE ÁGUAS. MINISTÉRIO DO MEIO AMBIENTE. Programa das Nações Unidas para o Meio Ambiente. Cuidando das águas: soluções para melhorar a qualidade dos recursos hídricos. 2.ed. Brasília, 2013.

APHA - AWWA - WPCF. American Public Health Association; American Water Work Association; Water Environment Federation. Standard methods for the examination of water and wastewater. Rodger B. BAIRD, Andrew D. CLESCERI; American Public Health Association: Washington, 19th.edition, 2006.

ARAÚJO, G. F. R. et al. Qualidade físico-química e microbiológica da água para o consumo humano e a relação com a saúde: estudo em uma comunidade rural no estado de São Paulo. Revista 0 Mundo da Saúde, v. 35, n. 1, p. 98-104, 2011.

BEZERRA, A. D. A. et al. Análise da potabilidade de água de chafarizes de dois bairros do município de Fortaleza-CE. Revista Acta Biomedica Brasiliensia, v. 8, n. 1, 2017.

BRASIL. Ministério da Saúde. Portaria de Consolidação no 5/2017. Dispõe sobre à "Consolidação das normas sobre as ação e os serviços de saúde do Sistema Único de Saúde". Anexo XX - Do controle e da Vigilância da Qualidade 
da Água para Consumo Humano e seu Padrão de Portabilidade (origem. PRTMS/GM 2914/2011). Brasília, 2017.

COSTA, C. L et al. Avaliação da qualidade das águas subterrâneas em poços do estado do Ceará, Brasil. Revista Ciências Biológicas e da Saúde, v.33, n.2, p.117-180, Londrina, 2012.

FUNASA, Fundação Nacional de Saúde. Manual prático de análise de água. 4⿳亠丷a edição. Brasília, 2013.

FUNASA, Fundação Nacional de Saúde. Manual de Controle da Qualidade da Água para Técnicos que Trabalham em ETAS. Brasília, 2014. 112 p.

GOMES, M. A. F. Água: sem ela seremos o planeta Marte de amanhã. Local: Embrapa, 2011.

LORDELO, L. M. K. et al. Qualidade físico-química da água para abastecimento humano em municípios do sertão da Bahia: um estudo considerando diversas fontes de suprimento. Revista Águas Subterrâneas, v. 32, n. 1, p. 97-105, 2018.

LUNA, C. F. Avaliação do impacto do Programa Um Milhão de Cisternas Rurais (P1MC) na Saúde: ocorrência de diarréia no Agreste Central de Pernambuco. Tese de Doutorado. Centro e Pesquisas Aggeu Magalhães. Recife-PE: Fundação Oswaldo Cruz, 2011.207p

MENEZES, J. C.; MACHADO, C. A.; NASCIMENTO, R. O. Uma análise científica da água. $V$ Colóquio Internacional "Educação e contemporaneidade", São Cristóvão: 2011.

NUNES N., F. A. Entre fontes, chafarizes e o dique: a introdução do sistema de abastecimento de água em Salvador. Revista FSA, Teresina, v. 11, n. 4, p.134157, 2014. 
QUIMIS. Aparelhos científico LDTA. Manual de Instruções do fotômetro de chama. Q498M. Diadema/SP. 2011.

SANTOS, M. C. et al. Determinação de propriedades físico-químicas de águas do chafariz do município de Cuité-PB. Revista Educação Ciências e Saúde, v. 6, n. 1, p. 17-35, jan./jun., 2019.

SILVA, F. S. M. Avaliação da qualidade da água de abastecimento do município de Jaçanã/RN. 2019. 57 f. Trabalho de Conclusão de Curso (Graduação em Licenciatura em Química), Centro de Educação e Saúde, Universidade Federal de Campina Grande, Paraíba, 2019.

SOARES, J. A. S. Gestão de recursos hídricos: conflito pelo uso da água no açude Epitácio Pessoa - PB. 2014. 123 f. Dissertação (Mestrado em Recursos Naturais) - Programa de Pós-Graduação em Recursos Naturais, Centro de Tecnologia e Recursos Naturais, Universidade Federal de Campina Grande, Paraíba, 2014.

VON SPERLING, M. Introdução à qualidade das águas e ao tratamento de esgotos. 4. ed. Belo Horizonte: UFMG, 2014.

\section{Agradecimentos}

Ao Conselho Nacional de Desenvolvimento Científico e Tecnológico - CNPq pelo financiamento da bolsa PIBIC/Propex- UFCG. 